\title{
Succinate Dehydrogenase Cytochrome b560 Subunit, Mitochondrial
}

National Cancer Institute

\section{Source}

National Cancer Institute. Succinate Dehydrogenase Cytochrome b560 Subunit,

Mitochondrial. NCI Thesaurus. Code C97778.

Succinate dehydrogenase cytochrome b560 subunit, mitochondrial (169 aa, $19 \mathrm{kDa}$ ) is encoded by the human SDHC gene. This protein is involved in the localization of succinate dehydrogenase. 